\title{
Desenmascaramiento del mundo contemporáneo en el mosaico narrativo de Vicente Luis Mora: Fred Cabeza de Vaca
}

\section{Unmasking the Contemporary World in Vicente Luis Mora's Narrative Mosaic: Fred Cabeza de Vaca}

\author{
Ana Calvo Revilla \\ Universidad CEU San Pablo \\ crevilla.ihum@ceu.es \\ ORCID iD: https://orcid.org/0000-0002-0286-5767
}

\section{RESUMEN}

Analizamos la propuesta narrativa de Vicente Luis Mora en Fred Cabeza de Vaca. Mediante diversos mecanismos narrativos y estructurales, como la estética fragmentaria y la quiebra del discurso narrativo, la hibridación genérica y el perspectivismo, el escritor disecciona la contemporaneidad desde dentro y fuera del sujeto y plantea cuestiones de índole filosófica y estética, como la aniquilación y desintegración del sujeto, el vacío existencial y la incognoscibilidad y la indescifrabilidad de lo real.

Palabras Clave: Vicente Luis Mora; Fred Cabeza de Vaca; estética fragmentaria; discurso narrativo; hibridación genérica.

\section{ABSTRACT}

We analyze Vicente Luis Mora's narrative proposal in Fred Cabeza de Vaca. Through various narrative and structural mechanisms, such as the fragmentary aesthetic and the breakdown of narrative discourse, the generic hybridization and perspectivism, the writer dissects contemporaneity from inside and outside of the subject and raises some questions of a philosophical and aesthetic nature, such as the annihilation and disintegration of the subject, the existential vacuum and the unknowableness and the indecipherableness of the real.

Key words: Vicente Luis Mora; Fred Cabeza de Vaca; Fragmentary aesthetic; Narrative discourse; Generic hybridization. 
El tema (a la vez metafísico y policial, a la vez psicológico y alegórico) es la investigación del alma secreta de un hombre, a través de las obras que ha construido, de las palabras que ha pronunciado, de los muchos destinos que ha roto.

Borges

LA NARRACIÓN DE LA VIDA DE UN YO AJENO

Podemos aplicar estas palabras que Borges dedicó con veintiséis años de edad a Citizen Kane de Orson Welles en la revista Sur a Fred Cabeza de Vaca (2017), de Vicente Luis Mora, una obra que, tras casi cinco años de escritura y revisión textual, le hizo merecedor del XXVIII Premio Torrente Ballester. Si el escritor argentino aludía entonces a la abrumadora rapsodia de escenas heterogéneas que presiden la obra cinematográfica, no es menor el laberíntico rompecabezas con que el escritor cordobés alza el imaginario del inexistente personaje que la protagoniza.

Fascinado por las luces y sombras que acompañan al ser humano, el autor hace de Fred un símbolo de la quiebra de la identidad y del deambular errático del hombre contemporáneo, que se mueve entre el cinismo, la obscenidad, el interés y el exceso. Atraído por las posibilidades narrativas que presenta la tarea del biógrafo ${ }^{1}$, Mora despliega su quehacer literario, crítico y teórico en una obra poliédrica y subversiva, en la que disecciona las bifurcaciones del yo de un erudito crítico de arte español que, llevado por la ambición y el afán lucrativo, tras explorar otros territorios, como el emblemático y legendario conquistador español, decidió ser artista.

Nada en la novela tiene su génesis en el azar. Dos citas -extraídas del libro XXXIV de Historia natural de Plinio y del discurso inaugural que John Ruskin pronunció en la Escuela de Arte de Cambridge- actúan de pórtico; como la obra enciclopédica clásica, Fred Cabeza de Vaca proporciona abundante información sobre su época y, como el crítico inglés, invita a reflexionar sobre el papel de la producción artística, mientras traza la disyuntiva entre el espíritu filantrópico o mercantilista a que se enfrentan artistas, críticos y escuelas especializadas. Estamos ante una novela rupturista y de agitación estética, en la que de manera fragmentaria y discontinua y con sostenido aliento narrativo y épico el autor rehúye los lugares comunes y se enfrenta a cuestiones de hondo calado intelectual, como el cuestionamiento del estatuto genérico de la obra literaria y la cognoscibilidad de la realidad.

${ }^{1}$ Como confiesa en unas declaraciones el escritor había sido seducido por las lecturas de Verano, la tercera parte de la autobiografia ficticia Escenas de una vida de provincias, de J. M. Coetzee y de la biografía del alcoholizado y suicida pintor expresionista, que trazó William Boyd en Nat Tate: un artista americano 1928-1960 -un personaje «que pudo existir y que, en cierta forma, existe y nos recuerda cuáles son o debieran ser los límites del arte» (Mora 2014)-. 
En la obra la profesora Natalia Santiago Fermi pretende reconstruir la poliédrica biografía póstuma de Fred Cabeza de Vaca, «uno de los mayores artistas que ha dado el mundo en el siglo XXI» $(2017 \mathrm{a}, 17)^{2}$ y «primer artista desde Juan Muñoz que, [...], triunfa y recibe el Premio Nacional de Artes Plásticas» (115). El encuentro del archivo del artista, un auténtico «archipiélago textual y documental» (Mora 2017b), determina el planteamiento narrativo de la novela. Esta se construye a partir de la investigación que la docente emprende para descifrar el enigma que rodea al polémico, provocador y abismal personaje y culmina con la imposibilidad de resolverlo, pues siempre permanece abierta la posibilidad de seleccionar y recombinar cada uno de esos archivos para emprender la creación de una narración diferente, de un nuevo significado.

Desde que Proust en Contre Sainte-Beuve (1971) cuestionara el método crítico y Wimsatt y Beardsley en «The Intentional Fallacy» (1954) sostuvieran que el significado de lo dicho o escrito no depende solo de lo que el autor quiso decir, desprestigiaran el intencionalismo y la búsqueda de correlatos entre la vida y obra del artista, han sido muchos los teóricos y críticos que han cuestionado la falacia biográfica. Es un tema que plantea el escritor en la advertencia preliminar:

Advertencia previa, que a estas alturas de la existencia de la especie humana sobre la Tierra no debería ser necesaria, por obvia y de sentido común, pero que debe ser recordada una vez más, y quizá con mayor ahínco que nunca, ante los profusos y pavorosos ejemplos de olvido constatables en los últimos años, coincidentes con la desaparición de la formación humanística:

Esto es una ficción.

Ante la sobrevaloración de las manifestaciones de la literatura del ego (autoficción, diarios, memorias, etc.), en esta compleja novela reticular y polifónica el autor despliega la imaginación y apuesta por la ficción, como se deduce también de las palabras del autor en una presentación del libro:

Cada vez soy más reacio a la tentación autobiográfica o autoficcional (también como lector) e intento convertir la imaginación en el ejercicio central de la escritura narrativa. Para mí es un desafío ver cómo aparece de la nada una persona real, verosímil, hacia la que puedes volcar emociones, aunque no sean agradables (como es el caso de Fred, un canalla que puede ejercer cierta fascinación, pero no deja por ello de ser reprobable) (Asensi 2017).

Con una estética polifónica y fragmentaria interroga Mora las tesis, que el new criticism incluyó entre sus máximas y Borges propuso en Pierre Menard, autor del Quijote (1939), cuando sostuvo que el auténtico significado de un

\footnotetext{
${ }^{2}$ A partir de este momento se citará siempre por la edición de Sexto Piso 2017.
} 
texto no se halla en el propio texto sino en la interpretación (Rodríguez 2005). Por este motivo no sorprende que una de las claves que enmarca la lectura de la obra venga subrayada por la narradora en el capítulo IV:

Uno de los mayores errores críticos que puede cometerse es la 'falacia biográfica': pensar que las obras artísticas vienen impulsadas siempre por vivencias personales del autor, o por resortes secretos de su periplo vital o afectivo. Nunca me han interesado las interpretaciones psicoanalíticas o psicobiográficas, ya sean de otros hacia otros, ya sean de otros hacia mí (119).

Quiebra el escritor el pacto autobiográfico y enfatiza el pacto novelesco (Lejeune 1973, 138) con la vida de un falso artista, que nace en 1980 y muere en los años 30 del siglo XXI, cuya aprehensión subjetiva del mundo se halla diseminada en una escritura reflexiva, escindida, dispersa e inacabada, como el alma, según la máxima de Humboldt que el autor incorpora: «lo que el alma es capaz de producir es siempre sólo fragmentario» (231).

Como precisa la académica en la introducción y a lo largo de los siete capítulos que conforman la primera y más extensa de las dos secciones que vertebran la obra, el cínico y desengañado protagonista deja con su gusto por la escritura múltiples huellas de su fragmentada y exhibicionista personalidad, de sus peripecias y hondas reflexiones sobre la creación artística, la estética, la impostura, el fraude, el descrédito y desprestigio del arte contemporáneo. Como Plinio en el primer libro de Historia natural, a través del primer prosaico paratexto introductorio, Natalia presenta el contenido de la sección, los títulos y la descripción de los capítulos, facilitando que el lector siga el diseño de la investigación. Mientras bucea en la biografía y trayectoria profesional del artista (orígenes biológicos y raíces afectivas, períodos de formación, consolidación y fama internacional, huellas de su legado, etc.), se ve obligada a operar con una amalgama dispersa de unidades de información y con una alambicada imbricación de discursos textuales ${ }^{3}$, a través de los cuales Fred proyecta especularmente múltiples imágenes de sí mismo, de su desdoblamiento y aniquilación.

${ }^{3}$ Son múltiples las visiones que ofrecen las anotaciones de los diarios y apuntes de unas memorias inconclusas; los fragmentos del libro Conversaciones con Eckermann, que recoge los diálogos mantenidos por el artista con el crítico homónimo; los borradores de las respuestas de Fred en algunas entrevistas; la transcripción de conversaciones telefónicas, videoconferencias y mesas redondas en las que participó; fragmentos de algunos catálogos de exposiciones; podcast; artículos propios y ajenos y entrevistas publicadas en la prensa $(E l$ Mundo, El Pasquín Semanal, El País) y en revistas especializadas o no; datos extraídos de biografías no autorizadas por el artista, como la realizada por Sara López Mencía; informes judiciales; extractos de las entradas de blogs pertenecientes a otras personas con alusiones a la personalidad o las polémicas generadas por el protagonista; citas textuales de obras literarias; entrevistas con amigos y amantes, entre otros. 
Con esta inmensa multiplicidad y heterogeneidad de componentes textuales -muchos son relatos dentro de un relato-, la profesora accede desde múltiples perspectivas al objeto de conocimiento y se enfrenta a unos materiales inconclusos: los enunciados lingüísticos de un sujeto escindido, que invita a quien lo contempla a asomarse a la nada del ser, al abismal horizonte que visionara Bernhard en Maestros antiguos:
Al fin y al cabo, el mayor placer nos lo dan los fragmentos, lo mismo que en la vida; al fin y al cabo, sentimos el mayor placer si la consideramos como fragmen- to, y qué horrible nos resulta el todo y nos resulta, en el fondo, la perfección acabada [...]. Desde hace mucho tiempo no podemos aguantar ya nuestra época como un todo, dijo, sólo si la vemos como fragmento nos resulta soportable. El todo y lo perfecto nos resultan insoportables (Bernhard 2003, 28).

Con estos fragmentos, que no llegan a conformar un universo coherente y cerrado sino un gran collage, Mora cuestiona los cauces narrativos tradicionales y reflexiona sobre los códigos estéticos y éticos. Mediante la estética del fragmento y la estructura discursiva reticular e intertextual, en la que se entremezclan diversas voces y discursos sociales, el texto atrapa como una araña al lector. Y este contempla una realidad inaprehensible, que se halla en constante cambio debido a la multiplicidad discursiva y al gran mosaico de personajes que desdoblan las visiones, como si de un coro trágico se tratara; el lector es conducido a rastrear inquisitivamente y descubrir los infinitos sentidos que se hallan diseminados dentro y fuera de la novela; alimenta la sensación de estar ante una obra inconclusa o un depósito de formas sin fronteras ni límites, que aguarda un significado cambiante, como expuso Genette de la obra borgiana (1976, 210).

La estética del collage es la plasmación formal-literaria de los presupuestos teóricos del autor, tanto de la ruptura de la falacia biográfica y del desdoblamiento semántico del símbolo, como del papel esencial que juegan los vacíos o lugares de indeterminación en la obra literaria, en suma, de la reivindicación del derecho a novelar el vacío y la ausencia, siguiendo la concepción barthesiana: «dígase lo que se diga de la obra queda siempre, como en su primer momento, lenguaje, sujeto, ausencia» (Barthes 1971, 75). Fred Cabeza de Vaca, construida con un paradigma estético fragmentario y experimental, se asienta sobre la concepción de la ficción como un laboratorio semiótico y metaliterario, en el que se confunden los planos narrativos y se modifican las categorías de tiempo y espacio. Mora plantea el desafío hermenéutico de cómo ha de contarse una vida:

¿Cómo se cuenta una vida, cómo se destruye un relato existencial, cómo se levanta una biografía, con qué materiales? ¿Debe tender a la totalidad, debe detenerse sólo en los aspectos relevantes? ¿Debe ser un mosaico o una carretera? ¿Qué 
merece quedar dentro del recuento, y qué fuera de él? La biografía como relato de un relato (192).

Prolonga el escritor así algunos de los retos epistemológicos que ya había abordado en Alba Cromm, como: la imposibilidad de autografiar la vida de un yo vacío, de un sujeto que «para terminar y para comenzar no es» (Barthes 1971, 27); la dificultad de narrar la vida de alguien desde las memorias o la biografía; el modo de escritura propicio para reconstruir otro yo y el papel del biógrafo como sujeto afectado por la escritura ajena. Como James Boswell en Life of Samuel Johnson, LL. D., opera desde la ficcionalidad con la credibilidad del buen biógrafo, como manifiesta la narradora:

Los intentos anteriores de recapitular la vida del artista, que tendían más al escándalo morboso que al estudio integral y desapasionado de la persona vista desde su trabajo artístico y no al revés, sólo han encontrado el rechazo de la crítica especializada y el desinterés de los lectores (17).

Sin desdeñar el esfuerzo «de precisión, de imparcialidad revisora» (17) que requiere la objetividad del género biográfico en la representación del pasado -la veracidad, el tratamiento de la vida entera, la honestidad, la identificación de las fuentes o la fiabilidad, (Caballé 2012)-, la profesora hace vertebrar en torno a este aparente núcleo narrativo su investigación:

Los especialistas en literatura autobiográfica suelen acostumbrar el alejamiento aséptico respecto a la persona retratada, pero no podemos obviar que durante muchos años he sido una aplicada estudiosa de su obra, que hemos sido amigos y que he comisariado puntualmente alguna de sus muestras en su última etapa creativa (30).

Sin embargo, no es uno solo el eje que configura la narración sino una tupida red dialógica a través de la cual se deconstruye la identidad del biografiado, un pícaro triunfador que alcanzó renombre internacional, «la cumbre de toda buena fortuna» (15), cuya personalidad egocéntrica y contradictoria se muestra inasible, pues son muchas las máscaras tras las cuales se manifiesta y oculta a un mismo tiempo. A través de este personaje, con el que mantiene una relación deliberadamente hostil, el escritor cordobés plantea la crisis de la noción de sujeto que la modernidad heredó del mundo clásico. Prosigue la estela de los primeros cultivadores del género: el intento concienzudo e imparcial por rescatar los pliegues arcanos, psicológicos y morales, de un artista con tantas aristas que, a diferencia de los personajes biografiados por Plutarco en Vidas paralelas, no es modelo de rectitud, sino un crápula provocador, dilapidador y arribista, que se mueve sin escrúpulos y con escandalosa ligereza entre las nauseabundas aguas de la infame «connivencia del arte con la política y la mercadería» (16), mientras se esconde tras sus piezas creativas. 


\section{ESTÉTICA ESPECULAR Y POÉTICA DE LA INSUFICIENCIA}

Partiendo de la concepción barthesiana del biografema como aquello que se escribe de la persona a quien se ama, que induce al biógrafo a reprocesar los momentos vivenciados y almacenados en la memoria y a recopilarlos de manera fragmentaria -así lo expuso el semiólogo francés en Roland Barthes por Roland Barthes: «Escribir por fragmentos: los fragmentos son entonces las piedras sobre el borde del círculo: me explayo en redondo: todo mi pequeño universo está hecho migajas: en el centro, ¿qué?» (2004, 126)-, Natalia intenta descifrar el enigma que se oculta tras la personalidad narcisista del artista con el método que propuso Claudio Magris en «Biografía y novela» (29) y que inserta íntegramente en uno de los esquejes:

Si una biografía aparece rota en pedazos, cada uno de estos pedazos posee, en mayor medida aún, una realidad propia indeleble. Una realidad que seguramente se perdería si el fragmento fuese simplemente integrado, como un ladrillo, en el armonioso edificio de una biografía tradicional (184).

Este principio constructivo rige la arquitectura compositiva y las estrategias narrativas especulares sobre las que asienta la obra: el fragmentarismo, el perspectivismo, el discurso polifónico y la búsqueda de la verosimilitud. Como sostiene el escritor, hubiera sido una impostura crear una novela unitaria partiendo de la diseminación del sujeto biografiado pues, a pesar de los esfuerzos continuados de Fred por tomar registro nemotécnico y contarse a sí mismo a través del relato de su vida y a pesar de los intentos de la biógrafa por retrascribir la sobrenarración de ese yo ficcional y otras escrituras y oralidades, se pone de relieve la imposibilidad de acoger en su integridad la imagen poliédrica del biografiado. Los diversos hilos narrativos y temporales se mezclan y superponen de manera caótica y sin linealidad cronológica, lo que perturba la consecución del proyecto.

Aunque la fragmentariedad -según confiesa el autor en la entrevista de Alberto Moyano (2017) - viene motivada por el material con el que trabaja la biógrafa, responde también a la hiperconsciente configuración narratológica que la preside. La escritura del fragmento es la estructura narratológica a través de la cual Mora plasma con precisión la disolución del yo cartesiano y la conciencia de lo múltiple, los «movimientos de individuación» de los «mil pequeños sujetos larvarios, mil pequeños yos [moi] disueltos, mil pasividades y hormigueos allí donde ayer reinaba el sujeto soberano» (Foucault 1999, 328). El escritor, como Hoffmann en Opiniones del gato Murr, muestra la imposibilidad de narrar de manera unívoca la maraña de relaciones afectivas y profesionales de un individuo, cuyo pensamiento se disemina en una multiplicidad discursiva y en una escritura fragmentaria, espejo donde se refleja el desmoronamiento de un orden esencial: «existe sólo el agitado oleaje de la vida, sólo 
la corriente del devenir, el inacabado vaivén de sus olas. No hay nada duradero, permanente, estable; todo está sometido al movimiento» (Fink 1976, 194).

La fragmentariedad forma parte de la tensión narrativa y dimensión estructural de la novela; los fragmentos escritos por la biógrafa, que ha tenido el privilegio de mantener un «constante acceso al artista durante varias décadas» (30), se ven continuamente quebrantados e interrumpidos por otras unidades fragmentarias que, salvo ligeras excepciones, se insertan en el texto con los paratextos correspondientes, los cuales están asimismo sujetos a variantes textuales ${ }^{4}$. De esta manera la crítica realiza la lectura de una obra que se halla sometida a un proceso continuo de variación y reescritura, prueba de que, como dijera Barthes, «toda escritura que no miente designa, no los atributos interiores del sujeto, sino su ausencia» $(1971,73)$.

A medida que Natalia recaba información mientras entrevista a los habitantes de Albelda de Iregua (la maestra de escuela, Pablo el afilador, o Mayte la primera novia, etc.), va destejiendo las capas de silencio que rodearon la niñez y adolescencia de Fred y la intrahistoria del pueblo natal: el suicidio del padre y la difícil relación con su madre - «una esquinada mujer» de mala crianza que se fue a Madrid (23)-, su carácter atormentado, las complejas relaciones que entabla con el género femenino desde su adolescencia. Aunque las historias que narran quienes las protagonizaron y fueron testigos de los acontecimientos se

${ }^{4}$ Son numerosísimos los materiales dispersos a lo largo de la obra, como: «Materiales para insertar en esta parte» (31); « [Apuntes para memorias]» $(31 ; 33-34 ; 38 ; 38-39 ; 59-61$; $67-68 ; 82 ; 113 ; 127 ; 143 ; 153-156 ; 190-192 ; 247 ; 274-279 ; 285)$; «[Comentario]» $(31 ; 35$; $37 ; 59 ; 61 ; 61-63 ; 75-76 ; 78-79 ; 92 ; 98-99 ; 111-112 ; 118 ; 120-121 ; 143-144 ; 194 ; 273 ; 280$; 283; 319-325); «Esqueje» (32; 64-67; 68; 82-83; 92-93; 100; 114-115; 123-127; 129; 132-142; 147-149; 161-163; 172-175; 184; 188-190; 192; 202-204; 205-207; 248; 259-261; 262-267; $269-270 ; 281-282 ; 284-285 ; 286-288 ; 281-282 ; 296-304 ; 305-307)$; « [Diario] » $(32 ; 34 ; 63$; 69-73; 74-75; 76-77; 77-78; 79-81; 81-82; 83-84; 94-95; 105-106; 107-111; 115-118 121-122; $144-146 ; 156-158 ; 179 ; 187-188 ; 192-193 ; 194-195 ; 196 ; 200-201 ; 202 ; 204-205 ; 245-246$; 248-249; 261-262; 267-269; 270-272; 280-281; 282-283; 289-290; 304-305; 307); artículos propios $(251-259 ; 288-289)$ y de autoría ajena $(35-37 ; 48-55 ; 103-105 ; 112 ; 150 ; 169-171)$; Conversaciones con Eckermann, introducidas en unas ocasiones con autonomía textual (39$42 ; 56-59 ; 151-153 ; 163-165 ; 166-169 ; 175-179 ; 308-309)$ y en otras, incorporadas dentro de las reflexiones de Natalia (44-45); entrevistas (73-74; 99-100); grabaciones, como «[820hi5/24rich]» (91-92); transcripciones de mesas redondas en las que participa el artista (95-96); «[Borrador de email]» (97-98) y trascripciones de email (100-102; 295; 295-296); obras inéditas del artista (107); fragmentos de podcast (127-128); fragmentos de textos de Fred para catálogos (131-132; 293-295); informes jurídicos (158-160); anotaciones manuscritas del artista de contenido erótico, como «[c126856.2025.9n5]» (185-187) y «[klñ.98.2025. n95]» (196-200), algunas de ellas sin datación cronológica (193-194; 318; 318-319); postales de Fred $(195 ; 280)$; extractos de entradas de blogs (201-202) y extractos procedente de la prensa (246); fragmentos de la biografía no autorizada de Freddy Cabeza de Vaca (249251); fragmentos de obras inventadas, como el ensayo Historia del arte y las ideas estéticas del primer tercio del siglo XXI, de Juan Martín Prada (290-291), etc. 
van entrelazando y creando cierta sensación de unidad narrativa, las distintas interpretaciones van introduciendo en el lector la duda, la sospecha y la quiebra de toda certeza.

Si los escritos autobiográficos del artista reproducen con precisión la desintegración del yo y subrayan el vacío que impera en su existencia, la intercalación de esquejes y comentarios fragmentarios por parte de la biógrafa potencian el montaje compositivo y enfatizan la búsqueda de sentido que esconde el no decir del fragmento y la expresión de la totalidad a través de pensamientos esencialistas, que permiten «captar detalles insospechados y lograr instantes de alta tensión, congelados como consecuencia de la abrupta conclusión de las secuencias» (Noguerol 2012). En ambos casos la totalidad de la cosmovisión y su imposibilidad están en el germen de la elección del fragmento como soporte narrativo especular y reticular, a través del cual el sujeto se contempla a sí mismo y proyecta una imagen hacia fuera, mostrando la dialéctica que existe entre «escribir, leer, mirar y ser mirado» (Topuzian 2018), como acertadamente expresa la biógrafa en este comentario: «Están escritos para sí, pero con un ojo puesto en los otros, como esos adolescentes que posan al moverse, pensando que alguien graba y analiza sus acciones» (283).

A semejanza del mundo vegetal crecen en la obra los esquejes, breves textos fragmentarios que no se atienen a una subordinación jerárquica (Deleuze y Guattari 2015, 35) y albergan relatos dentro del relato. Mientras el primer esqueje contiene el germen inicial de la novela, en los sucesivos Natalia va tejiendo, como las míticas Atenea o Ariadna, los hilos heteróclitos y heterogéneos que le proporcionan algunas personas con las que Fred mantuvo relación (afectiva y profesional): «detalles, hechos, gestos que harán cambiar su imagen pública» (64); mientras trenza unos hilos con otros conoce al artista desde otros ángulos de visión, reinterpreta y descifra sus aspectos más arcanos, sin saber si atisbará el camino que le permita entrar en el laberinto del monstruoso minotauro, canalla impostor y manipulador, que maneja a su antojo los hilos del mundo del arte, como se percibe en la conversación telefónica que mantiene en 2016 con un desesperado y suicida Basquiat, que se ofrece a realizar una fotografía del ojo de Fred para reproducirla en Venecia bajo el paratexto Fragmento de Freddy Cabeza de Vaca (ojo crítico). Pretende Natalia desmentir, como afirma en el esqueje 3, la biografía no autorizada que Sara López Mencía tituló provocativa y mediáticamente como Revol(u)c(i)ones, mientras cuestiona desde la admiración inicial unas palabras del artista, que la biógrafa había reproducido y con las que parafrasea el significado del alter ego SAMO -siglas de Same Old shit, «la misma mierda de siempre»- con que firmaba sus grafitis el pintor estadounidense: «-No lo entiendes, Sara. Todos somos un inmenso costal de mierda. Todos. Ni uno se salva» (149).

Si el hecho de tejer las hebras condensa una metáfora del destino humano, observamos que Mora entabla también un juego lúdico, intelectual y estético con otros recursos, como la distribución aleatoria de la información al transcri- 
bir en letra cursiva el contenido de 27 esquejes, entre los 38 numerados; la concesión de idéntica designación numérica a esquejes de contenido diferente (por ejemplo, el número 7), la alteración del orden señalado por la numeración de los esquejes, lo que incrementa la posibilidad de trazar itinerarios de lectura distintos de los que la obra propone. A medida que el lector toma conciencia de la fragmentariedad y de la alteración del orden cronológico con que sucedieron los acontecimientos - algunos proyectados en el futuro-, la comprensión del personaje disminuye, «cayendo en una completa desconexión y abriéndose a abismos de oscuridad y de nada, de los que únicamente surgen dolorosos retazos» (Magris 1999).

Los diecinueve comentarios que la investigadora intercala con una tipología gráfica diferente (en cursiva) desempeñan asimismo un papel destacado en la hermenéutica biográfica, pues en ellos -salvo una excepción, que contiene la respuesta dialógica de la profesora al caos que impera inicialmente en la clasificación archivística de la obra por parte del artista moraliano (246)- procura develar el significado de los textos autobiográficos del decadente y turbio dandy baudeleriano, para que el lector pueda llenar los vacíos o huecos de indeterminación ${ }^{5}$.

Teniendo en cuenta que «el fragmento encuentra su sentido tanto en el decir como en el no decir, en la parcial ausencia o silenciamiento de sentido» (Mora 2015, 97), la estructura fragmentaria posibilita la presencia del sujeto bajo los significantes elididos que el yo cree haber expulsado, allí donde no se

${ }^{5}$ Se trata de pequeñas glosas relativas a las referencias numéricas con que acompaña sus relaciones afectivas desde el inicial cero, con que alude a su madre (31); la caligrafía como criterio de datación cronológica en sus anotaciones (35); los proyectos artísticos desde sus años universitarios (37); las condiciones fijadas por el artista en sus entrevistas, como la revisión textual antes de su entrega a la imprenta (59); el machismo exacerbado que exhibe en sus diarios mediante la objetuación y degradación de la mujer, incluida quien fue su única relación amorosa profunda: Gabriela Háfiz Cote, a quien nunca llamó por su nombre sino como 54 (61); el oscurantismo de algunas prácticas habituales repulsivas, como la grabación a escondidas de los entrevistados (92) o de las mujeres con las que se acostaba (excepto Gabriela), que custodia en su ordenador con archivos numéricos para subirlas a la plataforma de microbbling Tumblr en la cuenta que mantuvo actualizada hasta treinta días antes de morir (99); la ausencia de límites en el comportamiento sexual de quien asume con indiferencia «su nuevo estatus de sobjeto, de ente subjetivo cosificado en objeto» (111); la repercusión mediática que persigue con su arte, como la muestra de fotografías deslumbradas «Solaroids», que Natalia describe como imágenes fosfénicas, a las que atribuye el concepto afterimage, relativo a las imágenes que perduran en la visión tras desaparecer el origen que las alumbró (118); la red vista como un sosias inconsciente, que materializa como un doppelgänger los aspectos más sórdidos del ser humano (121); los móviles económicos de su actividad curatorial (144); las prácticas fraudulentas a través de las cuales conseguía muestras y subvenciones (260); los planteamientos mentales recurrentes del obsesivo artista, «cuyo efecto era retrotraerle a una cadena de ideas incesante, ad absurdum» (273) o el culto narcisista a la propia imagen con que se rinde tributo (283), entre otros. 
le espera ni donde el yo parece enunciar. Y se convierte en medio de expresión estética, que representa la crisis de nuestro tiempo e ilustra «la idea de que un conocimiento completo del mundo es, en realidad, imposible, pura apariencia, un espejismo, la ilusión vana de dicho conocimiento» (Saldaña 2009, 222); es decir, es la textura discursiva de la «estética de la insuficiencia», con la que el individuo muestra la desintegración interior y la «melancolía de saberse sin reposo» (Reixach 2004-2006, 578). La escritura discontinua y fragmentaria de Fred es el espejo en el que se refleja un sujeto carente de centro (Talens 2000, 80), disperso y errante, que estalla y se rompe en añicos (Paz 1999, 315). Partiendo de la tipología trazada por Shattuck en The Innocent Eye (1984) entre fragmento absoluto, fragmento implicado, que no existe sin relación a otros fragmentos o a un todo, y fragmento ambiguo, con un pie en ambos lados, nos encontramos ante la escritura fragmentaria de una identidad ambigua, "conflictiva, tensional, errátil y dirigida a la destrucción de la idea de conjunto; huye centrífuga y desordenadamente, se mueve hacia la dispersión y la rotura» (Mora $2015,95)$, cuya biografía se convierte en un imposible de alcanzar ontológica y lingüísticamente. Estamos ante un artificio narrativo proteico y multiforme, que cuestiona la estabilidad de un universo que permanece sujeto al error, a la relatividad del tiempo y al cambio incesante; su estética fragmentaria ficcional es la imagen especular de un mundo fragmentado y en crisis, de una realidad socio-cultural, ideológica y artística que ha cambiado.

Mientras que la escritura biográfica se alza como un espejo que devuelve la imagen del biografiado, la estructura fragmentaria de esta novela inconclusa en su germen narrativo (fracasa la intencionalidad del proyecto de Natalia) la cuestiona, al tiempo que encierra una concepción filosófica y epistemológica esencial: la incognoscibilidad e indescifrabilidad de lo real, que Fred condensa en esta anotación del diario, fechada en 1999, en plena juventud:

La realidad me parece incognoscible, una suma de fenómenos desmembrados. Voy por la calle con los ojos abiertos, pero no entiendo nada. Es como si estuviera ciego, aunque puedo ver. Nada me resulta descifrable. Todo me sorprende y parece regido por una lógica que no comprendo. De modo que no me sirve de nada la vista. Soy un invidente funcional. Todo acontece para otros, o para otra dimensión, o en otras coordenadas. Lo que tengo ante mis ojos no es significativo, no habla. No me dice nada. La realidad es una fórmula matemática resuelta, pero mirada por un alguien inexperto: tienes la solución delante, está ahí, frente a tus ojos. Pero ni siquiera eres capaz de distinguir el resultado del resto del problema. Si careces del método y los ojos adecuados, es como mirar rayas en la roca, formas en las nubes, trazos perpetrados por un niño (34).

Subyace de manera implícita e irónica esta tesis en el recurso intertextual a la ceguera de Gabriela Háfiz, con la que el autor vuelve a teñir la escritura de tintes borgeanos: el espejo, el laberinto, etc.; si para este, la ceguera no es una desdicha sino un instrumento y un don, también lo es para Mora, quien 
juega con el binomio que forman la ceguera y la máxima de Goethe de que «todo lo cercano se aleja» («Alles Nahe werde fern»), a la que aludió el escritor argentino en la conferencia pronunciada en 1977 en el Teatro Coliseo de Buenos Aires, que publicó en Siete noches.

El discurso narrativo está integrado también por un coro polifónico de instancias narrativas (Fred, críticos de arte, amantes, etc.), cada una de las cuales introduce un punto de vista y una amplia variedad de registros: ironía, parodia, diatriba, invectiva, etc. Estos hilos narrativos, que se bifurcan laberínticamente, se alzan como ejes narrativos a través de los cuales procura la biógrafa alcanzar el propósito trazado, mientras se cuestiona la posibilidad de lograrlo en su totalidad. Como si de un rompecabezas se tratara, mientras los personajes van recorriendo el sendero que configura el artificio laberíntico, se va conformando una estructura narrativa coherente. El perspectivismo contribuye a que esta, aun girando en torno a un núcleo (la reconstrucción biográfica del protagonista), no tenga únicamente un solo foco sino tantos como instancias narrativas convoca Natalia. También la ausencia de configuración lineal y la dispersión cronológica multiplican el efecto disruptivo y perturbador sobre el lector, que ha de adoptar una participación activa para deslindar la problematización que se le plantea.

Otro de los principios constructivos sobre los que se teje la novela es la búsqueda de la verosimilitud a través de recursos diversos, como la inclusión de documentación procedente de quienes conocieron al artista y escribieron o hablaron sobre él o la incorporación al mundo ficcional de personalidades intelectuales, que oscilan desde el crítico Arthur C. Danto, el artista conceptual japonés On Kawara (54) ${ }^{6}$, el escritor argentino César Aira (200), el poeta y ensayista polaco Adam Zagajewski (193), los españoles Miguel Ángel Hernández Navarro (95), Rafael Argullol, José Luis Brea (63), Félix de Azúa, Antonio Méndez Rubio (95), entre otros.

Fred Cabeza de Vaca dialoga intertextualmente con otras disciplinas artísticas, géneros literarios y autores diversos debidamente referenciados ${ }^{7}$, o transmutados mediante un genial juego de palabras en una carta gastronómica:

${ }^{6}$ No es el momento de trazar una relación entre la secuencialidad fragmentada y seriada del archivista On Kawara con el cultivo del archivo por parte del protagonista de la obra y de las prácticas artísticas contemporáneas.

${ }^{7}$ Nos referimos, entre otras, a Crítica del juicio, de Kant (157); Sobre el tiempo, de Norbert Elias (35); Bajo la red, de Iris Murdoch; Polaroids from the dead, de Douglas Coupland (36); Le mont analogue, de René Daumal (96); Los cerebros plateados, de Fritz Leiber (101); The Atrocity Exhition, de J. G. Ballard (103); Estigma. La identidad deteriorada, del sociólogo Ervin Goffman; La estructura de la realidad, de David Deutsch (157); Self comes to Mind, de Antonio Damasio (157); Libro del desasosiego, de Pessoa (206); referencias a Pynchon (49), Shakespare y Wilde (70), Proust (77), Novalis (96), Dostoievski (123), Sartre, Rilke, Nietzsche, Wells, Ralph Ellison y Furio Jesi (143), Georges DidiHuberman (176), Camus y Musil (202), Edward Said y Juan Goytisolo (262), etc. 
Estuve a punto de fotografiar la estúpida carta que nos trajeron, pero pensé que ella podría considerarlo un gesto de mal gusto (a Pascal todo le parecía de mal gusto, o eso parecían decir las miradas compungidas que nos dedicaba a los presentes no galos), así que me dediqué a memorizar, mientras hablaban en francés de sus cachupinadas y pijerías, la descerebrada lista de platos que transparentaba las ínfulas humanísticas del chef: de primero había Verduras Sartreadas, Hojaldres de SalMichon (esto, como es obvio, es lo que encargó el chauvinista como entrante), EnlaSada Daniel, Coktail de Gambattista Vico (se olvidaron una i, los paramecios), Tartina de Nueces Borgeso y Sopa de Gideos (109).

La ambiciosa novela parece concebida como un gran espacio creativo que alberga múltiples manifestaciones artísticas (unas inventadas ${ }^{8}$ y otras reales ${ }^{9}$ ) y acoge la heterogeneidad comunicativa y cultural del mundo contemporáneo (el espacio ebay, el spam y el correo electrónico, la agencia Reuters, los museos, las plataformas digitales...), al mismo tiempo que aprehende formal y estructuralmente la configuración rizomática y reticular mediante varios recursos, como el enfoque caleidoscópico, la discontinuidad y heterogeneidad discursiva, el abandono del hilo narrativo, la suspensión de la linealidad, los juegos prospectivos, la asepsia y disolución del personaje del nouveau roman, la reflexión metaliteraria, entre otros.

Fred Cabeza de Vaca se ensambla en el continuum eliotiano de la tradición literaria: en la novela picaresca y en la modernidad cervantina; en la novela psicológica y en la novela de formación goethiana (Bildungsroman); en la novela de artista y en la narrativa experimental; en la literatura existencialista de Camus, Kafka, Beckett o Melville y en la narrativa que dialoga con el arte contemporáneo mientras disecciona, destripa, cuestiona y redefine las formas literarias; en la narrativa reticular del siglo XXI que cultiva la microtextualidad

${ }^{8}$ Entre estas figuran las performances e instalaciones del artista denominadas «Celebriedad» (37), A Siria (86), Entierro (90), Cactus sobre papel (107) o Your Two Homes (175).

9 Son numerosas las referencias contenidas en la obra, como: la videoinstalación de Regina José Galindo (99) o Roden Crater, de James Turrell (100); la pintura en Todas las series, de On Kawara (54) y El auditorio del teatro del Castillo Viejo, de Klimt (272), el arte abstracto de Rothko, Pollock o Rauschenberg (65), el arte visual y conceptual de Joseph Kosuth (76), George Brecht (77), Cristina Iglesias, Anselm Kiefer, Juan Navarro Baldeweg y Sebastian Bienik (99), Arnold Böcklin, Paul Klee y Alberto Giacometti (274); el séptimo arte en Celebrity, de Woody Allen (35), Shortbus, de John Cameron (97) y Eyes Wide Shut, de Stanley Kubrick (198); el vídeo experimental Removed, de Naomi Uman (96) o Kaltes Klares Wasser, de Hester Scheurwater; el disco Celebrity Skin, de la banda Hole (36); la narrativa serial televisiva de Lost, Utopia, The Wire, Fargo, The Leftlovers, Boardwalk Empire (79), The Sopranos, House of Cards, The Walking Dead, Breaking Bad, True Detective (80); la obra fotográfica publicitaria de Guy Bourdin (96), Grae Andresen (97), Santiago Sierra (112), Herb Ritts (276) y Andreas Gursky (280); la escultura de Juan Muñoz (115); la arquitectura de Josef Hoffmann (110) o la crítica institucional de Hans Haacke (99), entre otras. 
o de la construcción paratáctica (Dällenbach 1977; Champeau 2011, 70; Mora 2015, 95-96).

Con la representación del mundo desde la perspectiva del sujeto Fred Cabeza de Vaca se inserta plenamente en la narrativa contemporánea, que recompone la multiplicidad y el caos (Eco 1984, 274). A través de la disolución del principio argumental, de la inserción de diferentes líneas narrativas y de la heterogeneidad genérica, discursiva y semiótica, Mora potencia la contigüidad dispositiva y la tensión dialéctica entre fragmento y totalidad; cuestiona la totalidad de sentido, enfatiza la poética del enigma mediante la proliferación de las significaciones que vierten las múltiples unidades narrativas, y otorga un primer plano a la recepción en el seno de la propia obra -un escrilector y una escrilectura (Senabre 2000, 16) - y fuera de ella, suscitando tantas lecturas como asociaciones temáticas o estructurales presentan sus ramificaciones.

Tras el abandono desde el renacimiento de la formulación geométrica de la representación de la perspectiva y tras la crisis que introdujo la teoría de la relatividad en las coordenadas espacio-temporales, las diferentes manifestaciones artísticas han ido incorporando el fragmentarismo, la superposición de los puntos de vista, el pluriperspectivismo, la conglomeración de elementos atomizados (collage) y las yuxtaposiciones insólitas, la dislocación de las estructuras (espacio y tiempo) y la hibridación discursiva. Vicente Luis Mora asimila estos principios constructivos en esta obra -una joyceana work in progress o una juanramoniana obra en marcha, que no tiene fin, como formula el artista Mecamp en una carta fechada el 23 de noviembre de 2031, en la que confirma que Natalia ha dejado inconcluso su trabajo (316)-, en la que toma cuerpo la imagen de un ser ficcional que evade el encasillamiento academicista y que encarna en todos los ámbitos de su vida (sexual, artística, profesional, etc.) todos los incestos y mezclas posibles, lo cual tanto desde el punto de vista temático como formal (el borrado, los silencios que operan formalmente entre cada fragmento, etc.) suscita la extrañeza (otranenie) en el lector, invitándolo a tomar parte activa en la lectura de las propuestas y cosmovisiones expuestas. El escritor traza con coherencia el edificio narrativo, mientras opera con gran libertad a través de la proyección de la temporalidad en un futuro visionario, que el lector, sin embargo, atisba muy próximo.

\section{UN HÍBRIDO ROMPECABEZAS DIABÓLICO}

Desde que Fowler (1982) o Schaeffer (1989) invitaran a abandonar las seguridades que aportan las clasificaciones genéricas para prestar atención al funcionamiento de las mismas (Besa 2014, 120), y desde que Genette en Fiction et diction (1991) incorporara dentro del ámbito literario la prosa no ficcional (textos filosóficos, históricos, epistolares, ensayísticos, etc.), que había sido desatendida por las teorías literarias aristotélica-mimética y formalista, son 
muchas las obras que, dentro del ámbito de la narrativa contemporánea han sido escritas desde la hibridez genérica y que con su naturaleza porosa y multiforme se muestran propensas a confundirse con otros géneros literarios (Gómez Trueba 2017).

En el fascinante rompecabezas diabólico de compleja clasificación que es Fred Cabeza de Vaca sobresale el pulso narrativo del escritor que, sin dejar de elaborar una novela de ideas, ofrece un texto ficcional híbrido, que inserta en la trama elementos autobiográficos y metaficcionales, paratextos apócrifos (artículos, catálogos de exposiciones, prólogo, notas a pie de página...) y digresiones ensayísticas, de manera que en el ensamblaje de crítica periodística (crónica, artículo, crítica, etc.) y géneros literarios diversos (aforismo, epístola, relato, etc.), los componentes no ficcionales parecen quedar «irreconocibles» (Alberca 2007, 287).

Sin renunciar al juego que dentro de la ficción entablan los elementos biográficos, autobiográficos y autoficcionales, plantea una trama metanarrativa, en la que están presentes cuestiones de fuerte arraigo teórico-literario, como: el pacto autobiográfico y novelesco; la paradójica tensión entre la ficción y la verosimilitud narrativa; la ruptura del horizonte de expectativas que entraña la tentación autoficcional al prescindir de la identidad nominal entre personaje y autor; la construcción de la identidad y su ocultamiento a través del esperpéntico blogopersonaje avatárico, el administrador Avonimus (305-307) que, como elemento ficcional inserto en la ficción, enfatiza la construcción atomista y devora y engulle la imagen del protagonista y de quienes lo rodean (306); el papel de los recursos paratextuales en el diseño de la narración avatárica; la construcción de un yo narcisista y exhibicionista y su deconstrucción fragmentaria; la concepción de la totalidad como un archipiélago de centros de fuerza que se dislocan del núcleo central y alejan al hombre del orden racional subyacente, pues este, presa de un enmarañado caos, no alcanza la inteligibilidad ni en el ámbito personal ni social; la prolongación de la narración en el espacio digital (blog, e-mail, spam, web, etc.) y, por lo tanto, de la lectura más allá del texto literario, invitando a surcar de manera explícita o sutilmente implícita algunos enlaces; la concepción ricoeuriana de la trama como concatenación de acontecimientos; la libertad artística y el cuestionamiento del todo vale creativo (200-201); el equilibrio entre la contención y el manierismo en el proceso creativo y la estimulación en el proceso de recepción (201), entre muchos otros.

Dado que Vicente Luis Mora concibe la escritura como «una representación parcial del mundo» y al escritor «un hermeneuta que descubre conspiraciones» -lo afirma en la bitácora Diario de lecturas (14/09/2017)-, se comprende que ponga sobre el tapete cuestiones de profundo calado intelectual a través de las cuales traslada las turbulencias y convulsiones del mundo circundante y la revisión y el cuestionamiento posmoderno del tiempo histórico (Ermarth 1992; Jameson 1996). Aúna en Fred Cabeza de Vaca el placer estético y la fuerza epistemológica textual (Schaeffer 1992, 475), permitiendo que la dimensión 
ensayística, con la apertura y aceptación de formas ficcionales y no ficcionales (Aullón de Haro 1992), cobre una dimensión relevante; lo logra a través de la presencia dramatizada de diversos sujetos de la enunciación que «provienen del mundo de las ideas: son filósofos, investigadores, críticos» (Mora 2017a, 9), cuyo pensamiento y saber sobre el mundo cristaliza en una escritura discontinua, que se ofrece fragmentariamente (Angenot 1982; Besa 2014, 117) y asume múltiples formas tanto en la vertiente científica (artículos, discursos, informes, panfletos...) como artística (crónica, biografía, memoria, confesiones, etc.). Estos discursos permiten que el escritor, mediante la pluralidad discursiva y la puesta en crisis del sistema genérico heredado de la racionalidad clásica, se articule «a sí mismo con su mundo histórico coetáneo» (Gracia y Ródenas 2008, 167), enfatice su concepción del mundo del arte como «un inmenso archipiélago de nódulos disímiles, distintos en cada país, ciudad y barrio» (Mora 2017c, 10) y emprenda la crítica de las ideologías (Luckacs 1975, 23; Aullón de Haro 2005).

A través de la sofisticada estructura reticular Mora proyecta como en un espejo roto las preocupaciones filosóficas, éticas y estéticas que han presidido su quehacer crítico hasta el momento, en La luz nueva. Singularidades en la narrativa española actual; Pasadizos. Espacios simbólicos entre arte y literatura o La literatura egódica. El sujeto narrativo a través del espejo. Siguiendo la línea trazada por Nietzsche y dibujada por Foucault de que la verdad no permanece ajena a las disputas que se crean en torno al poder y las instituciones, diserta sobre los mecanismos de entronización y legitimación del poder político y económico en la esfera artística tanto en el ámbito hispánico como internacional; entre la sátira y la ironía reflexiona sobre el contenido y el significado de los objetos artísticos, el relativismo cultural o la primacía de los procesos comunicativos; explora el terreno de las convenciones genéricas (la hibridez de la ficción, el relato autobiográfico y la reflexión ensayística) y de los límites referenciales de la ficción literaria; plantea la controversia posmoderna acerca de la posibilidad de dar cuenta de la realidad mediante discursos referenciales; aborda los límites del arte y la confluencia entre diversas esferas semióticas, entre la obra literaria y las tecnologías de la información y comunicación; cuestiona la desintegración de la identidad individual y social en la era mediática; se sumerge en las sombras de algunas prácticas artísticas y en las agonísticas luchas entre el arte, el poder (prestigio, dinero, visibilidad, etc.), la ética, la legalidad y la justicia; y cuestiona algunas de las mitificaciones más destacadas, como el apropiacionismo, la especulación, la divulgación y la visibilidad mediática, el feísmo constructivo, la sacralización de la banalidad, o las controvertidas relaciones entre sexualidad y creatividad, entre la pulsión sexual y la perversión del sentido, entre otras.

Confluyen en Fred Cabeza de Vaca la escritura y la teoría, la premeditada discontinuidad discursiva, la estética del fragmento barthesiana y la reflexión intelectual. Con una propuesta narrativa, entroncada en la posmodernidad, 
Mora pone énfasis en la revisión crítica de algunas prácticas culturales, artísticas y literarias vigentes (las inauguraciones nauseabundas, el narcisismo que precisa de cámaras y fotos, los acontecimientos artísticos globales, la representación literaria y los límites del concepto de novela, entre otros) o de índole filosófica, estética, ética, sociológica, etc., como la concepción sartreana del ser-en-sí, el nihilismo y vacío existencial de quien anhela colmar su insatisfacción a través de la imagen externa, buscando «el reciclaje, la reevaluación y la atribución de un nuevo sentido a cientos de objetos que lo habían perdido» (Kunz 2008, 35; Lipovetsky 1996, 53).

Da el escritor en Fred Cabeza de Vaca una vuelta de tuerca más al proceso de falsificación que siguió en Quimera 322, donde inventó «la escritura del crítico inexistente y también la del ficticio escritor reseñado» (Mora 2010c); funde en esta ocasión la escritura de un artista y crítico ficticio con la de otros críticos ficticios y reales, que despliegan su tarea en publicaciones reales y ficticias, lo que le permite desplegar por cauces múltiples el análisis teóricoliterario y estético a través de un proceso de simulacro reticular incesante; estrecha la interacción entre las instancias discursivas y semióticas que forman parte de la cadena de sentido (Alba Cromm), la fricción entre el discurso ficcional y factual con la incorporación de programas informáticos o fotografías (Circular 07. Las afueras; Pantel 2013, 58) y la resonancia polifónica de las prácticas sociales, creativas y críticas contemporáneas, que son textualizadas y materializadas por distintos sujetos de la enunciación, haciendo que la diégesis se extienda más allá del libro convencional, invitando a proseguir la lectura a través de la red. Si Max Aub se sirvió de sus apócrifos para «combatir la dirección dominante del arte contemporáneo», romper los vínculos con la tradición y hacer «brotar un arte nuevo, con un nuevo lenguaje, emancipado de la representación de la vida» (Oleza 2013,7) y si él con Alba Cromm parodió algunas formas populares de narración mediática (la publicidad, las revistas), en este entramado tapiz narrativo que es Fred Cabeza de Vaca prolonga la crítica a la contemporaneidad y uno de los interrogantes planteados por el bildungsroman alemán acerca de la posibilidad de que el individuo alcance la plenitud en la sociedad de su tiempo; si Goethe en Wilhem Meister y Hoffamn en El gato Murr lo resolvieron de manera antitética, Mora aporta una respuesta no desde las grandes utopías románticas sino desde la distopía venidera, pues si bien la novela está enraizada en la realidad histórica, como la narrativa de Margaret Atwood encierra un aire profético.

LA ESCISIÓN DEL SUJETO: ENTRE LOS ESPEJISMOS DE LA CONTEMPORANEIDAD Y LA DISTOPÍA

«He intentado varias veces en mi vida sentar cabeza, hasta que descubres que hay personas que nacen sin cabeza, y tú eres una» (268): esta anotación 
extraída del diario de Fred y fechada en 2029 es un espejo del artista (268). Bien lo supo captar Riki Blanco cuando seleccionó como ilustración de la cubierta del libro la imagen de un imán que se atrae a sí mismo. El aubiano y ensimismado personaje, esteta y buen orador, es el narciso de todos los tiempos; como los artistas finiseculares que «asumieron la autoconciencia como requisito previo al acto creador» (Segade 2008, 21), Fred se contempla a sí mismo ensimismado, hace de su identidad una «cuestión estética (Segade 2008, 25) y plasma con su yo hedonista y escindido la conciencia desfigurada de quien frente al mundo exterior no delimita sus límites y se muestra vulnerable, propenso a adoptar múltiples disfraces, mientras los demás asisten a su desintegración física, intelectual y espiritual.

Encontramos en la personalidad del protagonista dos de las tres vías a través de las cuales tomó cauce expresivo el asalto a la idea de sujeto (Oleza 2013, 5): el determinismo heredado del marxismo y el individualismo nietzscheano, que condena al individuo a permanecer sometido a los propios impulsos bajo una moral de esclavo, que lo destruye y encamina a ir contra sí mismo mediante la construcción de máscaras, que trastocan su identidad y lo convierten en «punto de encuentro de fuerzas psíquicas y sociales más bien que señor de ellas, el escenario de una cadena de conflictos, más que el autor de un drama o el autor de una historia» (Wellmer 1988, 117). Partiendo de la distinción que plantea Jenaro Talens en El sujeto vacio (2000) entre textos fragmentados, que presuponen una tradición literaria precedente sin la cual pierden su significado, y fragmentarios, cuyo fragmentarismo remite a la ausencia de centro, a «la destrucción de la idea de conjunto» que «se mueve hacia la dispersión y la rotura» y refleja una identidad «conflictiva, tensional, errátil» (Mora 2015), con el juego metaficcional que plantea el escritor fija el desdoblamiento y la dislocación del yo, la escisión del sujeto posmoderno y la destrucción de un sólido núcleo identitario.

Dado que, como afirma Manuel Segade en Narciso, fin de siglo, «la identidad es una cuestión de estética, un problema de representación» $(2008,25)$, Fred cuestiona filosófica y vitalmente la identidad del sujeto y representa los límites de la identidad y «la metaescritura de uno (mismo) con un mayor o menor grado de ficción y teoría» (Mora 2013, 142). Emprende el autor en esta obra, en la que convergen biografía, autobiografía y metaconstrucción narrativa, una cartografía escritural del yo a través de la representación ficcional de las veladuras tras las que se oculta y expone a un mismo tiempo y desde la narración del vacío y las fracturas ontológicas que sufre el sujeto (Mora 2013, $103 ; 168)$, perceptibles en la adopción por parte de Fred de diversos constructos identitarios, en la proyección de su desazón en un incesante quehacer creativo y en los intentos frustrados en la reconstrucción identitaria del artista. A través de la escritura incesante del sujeto brota el anhelo de construirse un yo, que nunca es idéntico a sí mismo, sujeto a un continuo devenir y transformación, como hace constar con su deambular sexual de un cuerpo a otro, de un 
trabajo a otro y con el asedio fenomenológico con que registra obsesivamente su entorno. De manera especular lo formula el artista en «Metanoias», el texto que preparó para el catálogo de Ramiro Mecamp: «Imaginemos a un ser que persevera no en la idea de una identidad monádica y parmenideana, idéntica a sí misma, sino que ahonda o bucea en la perseverancia de una identidad metanoica, metamórfica, transformadora, en sucesión» (293). Asimismo, la imagen digital que se construye el artista para destruir a los demás y destruirse a sí mismo es reflejo de la notredad, de la fugacidad efímera y contingente que «se expresa con la volátil gramática de una sombra breve, de la fulminación, del relámpago sordo y puntual, sin eco» (Brea 2007, 153).

Dentro de la configuración estética del escritor, Fred Cabeza de Vaca es una obra comprometida con la literatura como instrumento de conocimiento de la contemporaneidad y de indagación distópica. Con el caudal imaginativo que le proporciona el género (Mora 2017c, 9) y con un profundo conocimiento de la tradición literaria y filosófica, el escritor disecciona la contemporaneidad, explora los interrogantes que plantea y los proyecta en un futuro disgregado. Siguiendo la estela de los grandes maestros (Wells, Zamiatín, Rad, Kapek, Huxley, Orwell, Bradbury) ofrece con su tono apocalíptico un panorama caleidoscópico sobre las problemáticas que se derivan de algunas prácticas sociales, artísticas y políticas contemporáneas (Booker 1994); rechaza el realismo que absolutiza el presente y perfila la estética del desencanto de los mundos aparentemente perfectos y planificados; da cauce narrativo a la reflexión sobre el modo en que el optimismo utópico ha derivado en el pesimismo brutal; percibe la fragmentariedad que brota de la desgarradora conciencia atomizada del hombre moderno y lo plasma narrativamente en la imagen de Fred, un anillo quebrado que no logra circundar nada, un sujeto alienado y atrapado por un sinfín de objetivos momentáneos y parciales, como expone Magris en El anillo de Clarisse. Tradición y nihilismo en la literatura moderna.

Mientras incorpora la crítica a la realidad política española (la transición, la cuestión catalana, la incorporación al euro [165], la propuesta de redacción de una Anticonstitución española que ampare la irresponsabilidad o la ilegalidad [126]), denuncia algunos aspectos perniciosos de la sociedad actual, como la decadencia moral perceptible en la misoginia, la degradación de la mujer, la esclavitud sexual, etc.; da forma fragmentada a los contrasentidos de la sociedad posmoderna y refleja la agonía del sujeto contemporáneo, que vive en una desorbitada exaltación del yo y se muestra incapaz de dotar de sentido a su existencia; aborda el tratamiento de la finísima línea que transita entre la farsa y el talento, entre la impostura y la genialidad, y prolonga la propuesta de transgresión epistemológica mediante la concepción del hedonismo y el arte como formas alternativas de conocimiento. Es Cabeza de Vaca un trepa sexual, que se complace en el mal y propaga la divinización de la estética; a través de sus intervenciones artísticas prolongación metonímica del hiato «que se abre entre el yo y la vida»-como afirma Magris en la introducción a La gran trilogía, de von Rez- 
zori- pretende hacer con su vida una obra de arte, lo que equivale en el mundo líquido a redefinirse perpetuamente (Bauman 2012). Su provocación no se encamina solo al individuo sino que adquiere dimensión gubernamental, como la creación de un Ministerio de la Basura y de la Subsecretaría de Arte y Reciclaje para administrar el problema de los residuos, que el escritor traza intelectualmente y desde una vertiente creativa en el «Brain Project» (251-259) o la exposición Morbutu, en la que construye «una loma artificial de cadáveres humanos, cortados por la mitad de un tajo y cuyo corte vertical se ha protegido con un cristal semicircular de metacrilato que deja ver los estratos de sedimentos idolátricos» (132); en otras ocasiones sus acciones se sitúan en un futuro posmoderno, como la videovigilancia cibernética que plantea en Cabezón, el panóptico que presagió Foucault en Vigilar y castigar: Nacimiento de la prisión, un Gran Hermano digital basado en «un sistema de registros de audio, micrófonos, telefonía, altavoces y sensores» (258), mediante el cual censura y socava el ataque a la privacidad que ejercen las compañías telefónicas; las relaciones con el robot-enfermero x15, que bautizó shakesperianamente con el nombre de Calibán, tiñéndolo de todas las resonancias de las reescrituras de Browning, Wilde, Joyce, Renan, Rubén Darío, etc. (291-292).

A través del protagonista insaciable de poder, manipulador, oportunista y corrupto que con su actuación convierte «la tierra en un infierno» (Popper 1967, 261), el escritor desentraña algunas claves del hombre que busca irresistiblemente la felicidad mientras se sumerge en una degradación sin límites y muestra con pesimismo antropológico hobbesiano que la violencia no pertenece a un tiempo lejano sino que reviste gran actualidad, pues el individuo para conseguir su bien es capaz de destruir al otro. Lo plasma con acierto en el tratamiento de la mujer; de manera semejante a como los súbditos del sistema, que protagonizan la novela distópica Nosotros del intelectual ruso, son números carentes de nombre propio, a los que distingue una clave alfanumérica, las mujeres en la vida de Fred no son designadas por sus nombres sino numéricamente; asimismo, las relaciones pasajeras y dramáticas con sus exparejas están pautadas por el placer, otro tipo de poder que todo lo devora y deshumaniza (112).

En el imaginario moraniano el cáncer como metáfora de un cuerpo extraño que invade la trayectoria vital del protagonista desde el trauma familiar, que lo trae «al mundo a martillazos» (309) y lo abandona a la soledad -es magistral la ternura con que su amigo Lerull lo describe en un correo que figura en el prólogo de Eckermann a Conversaciones con el artista (308)-, se alza también como metáfora del discurso autobiográfico, que brota incesante como una variante más de la palabra fin, con que la muerte pone fin a su vida. Asimismo, el tumor que crece sin medida es símbolo a través del cual el escritor evoca la ruptura del hombre en una multiplicidad de yoes sin sustancia, visualiza la sustancia «que estalla por los aires y se dispersa en múltiples fragmentos bajo las tesis del paleopositivismo de Carnap y Mach» (Peña 2002, 43) y desenmas- 
cara la degradación del orden personal y social que dibujó Musil en El hombre sin atributos, obligando al lector, por serle este mundo tan terriblemente cercano, a mirarse al espejo, mientras golpea su conciencia y lo sacude de su conformidad.

La propuesta literaria de Mora en Fred Cabeza de Vaca es un hervidero de historias y relatos laberínticos, a través de los cuales condensa diversas propuestas teóricas, filosóficas y literarias sobre el resquebrajamiento del sujeto cartesiano, «sujeto débil que rellena con una ficción sostenida el vacío, compensando la solidez perdida» (Mora 2013, 21) y su disolución en la ficción. El poderoso artificio literario y retórico sobre el que se asienta la personalidad astillada de Fred muestra la importancia tanto de la estructura narrativa y de la forma discursiva en la configuración de una novela como de la coherencia que ha de existir entre el personaje y los principios literarios que conforman el imaginario ficcional: un imaginario cultural, intelectual, ideológico e histórico, que es alcanzado por la fragmentación y por la ausencia identitaria, perceptible en la quiebra de las estructuras morales, políticas, institucionales y culturales, como plasma en las palabras extraídas de los apuntes para memorias de Fred que cierran la obra.

El interés del autor por la complejidad y fragmentariedad de la contemporaneidad es un aspecto clave de su pensamiento teórico, crítico y literario; es el reflejo de la conciencia de ruptura de un tiempo histórico que disuelve la idea de permanencia e imagen especular de la revolución estética que opera a través de la fusión de arte y vida. La novela, que prosigue la estética citacional (Pantel 2013, 60), se ramifica en diversos puntos de fuga; dibuja un mapa de escritura abierta, que se halla en un proceso continuo de transformación con el que invita al lector a reconstruir el significado que entabla cada fragmento con sus correspondencias, analogías y oposiciones.

De manera semejante a como Heine hizo de la representación el fundamento de una estética que rompió con el ideal clásico y romántico, Mora, al plantear la dialéctica entre linealidad y fragmentariedad, entre continuidad y discontinuidad (Champeau 2011, 80) y al cuestionar la autoría mediante la interacción de múltiples sujetos, se inmiscuye en la realidad contemporánea y la representa con sus paradojas en un nuevo territorio narrativo. Con un estilo irónico, lleno de improvisaciones y fragmentariedades, prolonga la quiebra de la linealidad narrativa, signo distintivo de la modernidad, busca nuevas formas de representar al hombre en su realidad fragmentada y encuentra en el fragmento la expresión estética de su visión del mundo. Fred Cabeza de Vaca es la praxis literaria de una teoría del texto (Barthes 1971), una narrativa de un formalismo estético-filosófico radical, circular y especular, que, como la de Borges, configura una visión de la escritura y de la ficción capaz de interpelar la esencia de lo real. En suma, una obra en la que cristaliza el pensamiento teórico y literario del autor. 


\section{FUENTES}

Asensi, Alfredo. 2017. «Vicente Luis Mora reflexiona sobre el arte actual en su novela más ambiciosa». El diario de Córdoba. https://www.eldiadecordoba.es/ocio/Vicente-LuisMora-reflexiona-ambiciosa_0_1175282575.html

Mora, Vicente Luis. 2010a. «El aleph en el espejo y el espejo como aleph: hacia una lectura transatlántica de Borges». En Nuevos hispanismos. ed. Julio Ortega, 267-288. Madrid: Iberoamericana - Vervuert.

Mora, Vicente Luis. 2010b. Quimera 322, septiembre.

Mora, Vicente Luis. 2010c. «E1 hoax de Quimera». Diario de lecturas. http://vicenteluismora. blogspot.com/2010/09/el-hoax-de-quimera.html

Mora, Vicente Luis. 2013. La literatura egódica. El sujeto narrativo a través del espejo. Valladolid: Universidad de Valladolid.

Mora, Vicente Luis. 2014. «El pintor que pudo existir». El Boomeran(g), 21 de octubre. https://www.elboomeran.com/vicente-luis-mora/41-el-pintor-que-pudo-existir/

Mora, Vicente Luis. 2015. «Fragmentarismo y fragmentalismo en la narrativa hispánica». Cuadernos hispanoamericanos 783: 91-103.

Mora, Vicente Luis. 2017a. Fred Cabeza de Vaca. México: Sexto Piso.

Mora, Vicente Luis. 2017b. «Entrevista a Vicente Luis Mora». A la carta. RNE.

Mora, Vicente Luis. 2017c. «Entrevista de Alberto Gordo a Vicente Luis Mora». El Cultural: 8-10.

Moyano, Alberto. 2017. «Entrevista a Vicente Luis Mora». El diario vasco. https://www. diariovasco.com/culturas/libros/vicente-luis-mora-20171024002200-ntvo.html

\section{BIBLIOGRAFÍA CITADA}

Alberca, Manuel. 2007. El pacto ambiguo. De la novela autobiográfica a la autoficción. Madrid: Biblioteca Nueva.

Angenot, Marc. 1982. La parole pamphlétaire: contribution à la typologie des discours modernes. París: Payot.

Aullón de Haro, Pedro. 1992. Teoría del ensayo como categoría polémica y programática en el marco de un sistema global de géneros. Madrid: Verbum.

Aullón de Haro, Pedro. 2005. «El género ensayo, los géneros ensayísticos y el sistema de géneros». En El ensayo como género literario, ed. Vicente Cervera, Belén Hernández y María Dolores Adsuar, 13-24. Murcia: Universidad de Murcia.

Bauman, Zygmun. 2012. El arte de la vida. De la vida como obra de arte. Barcelona: Paidós.

Barthes, Roland. 2004. Roland Barthes por Roland Barthes. Barcelona: Paidós.

Barthes, Roland. 1971. Critica y verdad. México: Siglo XXI.

Bernhard, Thomas. 2003. Los Maestros Antiguos. Madrid: Alianza Editorial.

Besa Camprubí, Carles. 2014. «El ensayo en la teoría de los géneros». Castilla. Estudios de Literatura 5: 101-123.

Booker, Keith M. 1994. The Dystopian Impulse in Modern Literature: Fiction as Social Criticism. Westport CT: Greenwood Press.

Borges, Jorge Luis. 1939. «Pierre Menard, autor del Quijote», Sur 4. En Obras Completas 1923-1972, 444-450. Buenos Aires: Emecé. 
Brea, José Luis. 2007. «Cambio de régimen escópico: del inconsciente óptico ala e-image». Estudios Visuales: Ensayo, Teoría y Crítica de la Cultura Visual y el Arte Contemporáneo 4: 145-163.

Caballé, Anna. 2012. «¿Cómo se escribe una biografía?». Rúbrica Contemporánea 1: 39-45.

Champeau, Geneviève. 2011. «Narratividad y relato reticular en la novela española actual». En Nuevos derroteros de la narrativa española actual, ed. Jean-François Carcelen, Geneviève Champeau, Georges Tyras y Fernando Valls, 69-88. Zaragoza: Prensas Universitarias de Zaragoza.

Dällenbach, Lucien. 1977. Le récit spéculaire. Essai sur la mise en abyme. París: Seuil.

Deleuze, Gilles y Félix Guattari. 2015. Rizoma. Valencia: Pre-Textos.

Eco, Umberto. 1984. Obra abierta. Barcelona: Ariel.

Ermarth, Elizabeth. 1992. Sequel to History. Postomodernism and the Crisis of Representational Time. Princeton. Princeton UP.

Fink, Euge. 1976. La filosofia de Nietzsche. Madrid: Alianza.

Foucault, Michel. 1999. Entre filosofía y literatura. Obras esenciales I. Barcelona: Paidós.

Fowler, Alaistair. 1982. Kinds of Literature. An Introduction to the Theory of Genres and Modes. Cambridge: Harvard UP.

Genette, Gérard. 1976. «Jorge Luis Borges». En Jorge Luis Borges, ed. Jaime Alazraki, 203-210. Madrid: Taurus.

Genette, Gérard. 1991. Fiction et diction. Paris: Seuil.

Gómez Trueba, Teresa. 2017. «Sobre la estética de la impostura: se buscan falsificadores de la novela actual». Artes del Ensayo. Revista Internacional sobre el Ensayo Hispánico 1: 23-42.

Gracia, Jordi y Domingo Ródenas, eds. 2008. El ensayo español. Siglo XX. Barcelona: Crítica.

Humboldt, Wilhelm von. 1989. Sobre la diversidad de la estructura del lenguaje humano y su influencia sobre el desarrollo espiritual de la humanidad. Barcelona: Anthropos.

Jameson, Fredric. 1996. Teoría de la postmodernidad. Madrid: Trotta.

Kunz, Marco. 2008. «Ni hamburguesa ni magdalena. En torno a Afterpop. La literatura de la implosión mediática, de Eloy Fernández Porta». Quimera 290: 32-36.

Lejeune, Philippe. 1973. «Le pacte autobiographique». Poétique 14: 137-162.

Lipovetsky, Gilles. 1996. La era del vacio. Barcelona: Anagrama.

Lukács. George. 1975. «Sobre la esencia y forma del ensayo». En El alma y las formas, ed. Manuel Sacristán. Barcelona: Grijalbo.

Magris, Claudio. 1999. «Biografía y novela». Revista de Occidente 220: 21-37.

Noguerol, Francisca. 2012. «Barroco frío: la última narrativa en español (1): el 'realismo histérico'». Imán. Revista de la Asociación Aragonesa de Escritores 6. https://revistaiman. es/barroco-frio/

Oleza, Joan. 2013. «El apócrifo, prototipo de una subjetividad en crisis». Asclepio. Revista de Historia de la Medicina y de la Ciencia 65 (2): 9. https://doi.org/10.3989/ asclepio.2013.15

Pantel, Alice. 2013. «Cuando el escritor se convierte en un hacker. Impacto de las nuevas tecnologías en la novela española actual (Vicente Luis Mora y Agustín Fernández Mallo)». Letral. Revista Electrónica de Estudios Transatlánticos 11: 54-69. https://revistaseug.ugr.es/index.php/letral/article/view/3747

Paz, Octavio. 1999. Obras completas, I. La casa de la presencia. Poesía e historia. Barcelona: Galaxia Gutenberg - Círculo de Lectores.

Peña Vidal, Jorge. 2002. Poética del tiempo. Ética y estética de la narración. Santiago de Chile: Editorial Universitaria.

Popper, Karl. 1967. La sociedad abierta y sus enemigos. Buenos Aires: Paidós. 
Proust, Marcel. 1971. Contre Sainte-Beuve précede de Pastiches et Melanges et suivi de Essais et articles. Paris: Pléiade.

Reixach, Amado. 2004-2006. «Contra “Uno”. La melancólica pulsión fragmentaria». Tropelías 15-17: 575-578.

Rodríguez Fernández, Mario. 2005. «Pierre Menard, autor del Quijote: biografía de un lector». Revista Chilena de Literatura 67: 103-112.

Saldaña, Alfredo. 2009. No todo es superficie. Poesía española y posmodernidad. Valladolid: Universidad de Valladolid.

Schaeffer, Jean-Marie. 1989. Qu'est-ce qu'un genre littéraire? París: Seuil.

Schaeffer, Jean-Marie. 1992. L'Art de l'âge moderne: l'esthétique et la philosophie del'art $d u$ XVIIIe siècle à nos jours. Paris: Gallimard.

Segade, Manuel. 2008. Narciso Fin de siglo. Barcelona: Melusina.

Senabre, Ricardo. 2000. «La novela entre dos siglos». Prosopopeya. Revista de Crítica Contemporánea 2: 7-19.

Shattuck, Roger. 1984. The Innocent Eye. On Modern Literature and the Arts. New York: Farrar, Straus and Giroux.

Talens, Jenaro. 2000. El sujeto vacío. Madrid: Cátedra.

Topuzian, Marcelo. 2018. «Fred Cabeza de Vaca». Otra Parte. http://revistaotraparte.com/ semanal/literatura-iberoamericana/fred-cabeza-de-vaca/

Wellmer, Albercht. 1988. «La dialéctica de la modernidad y postmodernidad». En Modernidad y postmodernidad, ed. Josep Picó, 103-140. Madrid: Alianza Editorial.

Wimsatt, William y Monroe C. Beardsley. 1954. «The Intentional Fallacy». En The Verbal Icon: Studies in the Meaning of Poetry, ed. William K. Wimsatt, 3-18. Lexington: Kentucky UP.

Fecha de recepción: 15 de noviembre de 2018 .

Fecha de aceptación: 06 de marzo de 2019. 